Research Article

\title{
Blended Teaching Design of College Students' Mental Health Education Course Based on Artificial Intelligence Flipped Class
}

\author{
Shan Shan ${ }^{1}$ and Yu Liu ${ }^{2}$ \\ ${ }^{1}$ College of Teacher Education, Harbin University, Harbin 150086, Heilongjiang, China \\ ${ }^{2}$ School of Control Engineering, Chengdu University of Information Technology, Chengdu 610000, Sichuan, China \\ Correspondence should be addressed to Yu Liu; liuyu123@cuit.edu.cn
}

Received 31 December 2020; Revised 4 February 2021; Accepted 20 February 2021; Published 3 March 2021

Academic Editor: Sang-Bing Tsai

Copyright (c) 2021 Shan Shan and Yu Liu. This is an open access article distributed under the Creative Commons Attribution License, which permits unrestricted use, distribution, and reproduction in any medium, provided the original work is properly cited.

\begin{abstract}
The current education methods are mostly based on test-oriented education and rarely really care about the content of students' concerns, and flipped psychological education methods have appeared in some areas. The main purpose of this thesis is to combine artificial intelligence and flipped classroom psychology. This article mainly introduces the characteristics of artificial intelligence and the definition of flipped classroom. What are the advantages of the intelligent teaching platform compared to traditional teaching? This article selects key 1 class, key 2 class, key 3 class, and key 4 class from the students of our school. Groups $\mathrm{A} 1$ and $\mathrm{B} 1$ conduct a semester of artificial intelligence combined with the concept of flipped classroom psychology. Groups A2 and B2 teach students in accordance with traditional teaching. The experimental results show that the proportion of groups A1 and B1 increased by $8.2 \%$ and $8.14 \%$. The midterm and final average scores of groups A1 and B1 are 10.87, 7.2, 14.13, and 12.2 points higher than those of groups A2 and B2, and their scores have increased by $10.3 \%$ and $7.02 \%, 12.4 \%$, and $11.9 \%$. The mental health education course effect of artificial intelligence and flipped classroom psychology can more stimulate students' interest and promote the improvement of students' performance through autonomous learning.
\end{abstract}

\section{Introduction}

Teachers can understand students' psychological state through their performance in class and after class and give them some psychological guidance, which is helpful to the improvement of students' academic performance. The curriculum of the talent training program complements each other. However, in actual teaching, teaching information between different courses is rarely interoperable, and the awareness of curriculum group construction is weak and superficial, resulting in loose curriculum relations. At the same time, students' knowledge transfer ability is not good; the possibility of independent integration of courses and forming a good three-dimensional cognitive structure is low. Therefore, it is necessary to integrate the curriculum, gradually break through the curriculum barriers, build a bridge between the previously separate courses and courses, and use more scientific teaching models to guide and assist students to effectively build a professional thinking system.

$\mathrm{Lu}$ et al. not only developed the next generation of artificial intelligence technology but also developed a new concept of general intelligent cognitive technology beyond AI. Specifically, we plan to develop an intelligent learning model called brain intelligence (BI), which can generate new ideas without experiencing events by using artificial life with imaginative functions. We will also show the developed Bi intelligent learning mode in the fields of automatic driving, precision medical treatment, and industrial robot $[1,2]$. Raza and Khosravi make a comprehensive and systematic literature review on the short-term load forecasting technology based on artificial intelligence. The main purpose of this study is to review, identify, evaluate, and analyze the performance and research gaps of load forecasting model based on artificial intelligence (AI). The accuracy of the neural network prediction model depends on the number of parameters such as 
the structure of the prediction model, input combination, network activation function, training algorithm, and other exogenous variables that affect the input of the prediction model [3]. Xiao proposed a new multisensor data fusion method based on evidence-based confidence measurement and confidence entropy. He designed a new Belief JensenShannon divergence to measure the ddifference and the degree of conflict between the evidence, and then through the obtained credibility, the reliability of evidence is indicated [4]. The array consists of quartz crystal microbalances (qcms), each of which is coated with different polymeric materials. The first method uses the decision tree classification algorithm to determine the minimum number of features needed to correctly classify training data. The second method uses the hill-climbing search algorithm to search the optimal minimum feature set in the feature space, so as to maximize the performance of neural network classifier. In order to reduce computation time, we also study the value of simple statistical processes that can be integrated into search algorithms [5]. The advantages and limitations of the two methods are discussed. Flexible pressure sensors based on organic materials combine the unique advantages of flexibility and low cost and have broad application prospects in artificial intelligence systems and wearable medical devices [6]. Zang et al. focus on the basic principles of flexible pressure sensors and then explore several key concepts of functional materials and optimized sensing devices to achieve practical applications. In addition, this study also discusses the development direction of self driving, transparent and implantable pressure sensing devices [7].

Elhoseny et al. produced four online video clips on endometrial hyperplasia, cervical dysplasia, adnexal mass assessment, and ovarian cancer, instructing students to watch these videos before active learning in class [8]. This study uses the open classroom learning management system to establish an open classroom learning activity management platform. Students are satisfied with both aspects of the flipped course. In addition, we also compared the National Board of Medical Examination (NBME) lectures on gynecological oncology before and after the implementation of the course and students' comprehensive performance on gynecological oncology problems [9]. Flipped classroom is a learner centered teaching method. Gilboy explains how to implement the flipped classroom and describes students' views on two undergraduate nutrition courses. The process described in the report has been successful for both teachers and students [10]. Peterson shows cumulative test scores and student evaluation data for two parts of my recent statistics course: a traditional lecture $(n=19)$ and a flipped classroom $(n=24)$. Independent sample $t$ test shows that students in flipped classroom scored one letter higher than their classmates in the final exam [11]. Tsai et al. used a simulation method to examine the relationship between benchmark tests and OKP, and how the knowledge inertia in benchmark tests affects OKP in different network structures. Their results show that fast benchmarking (low knowledge inertia) and moderate mutual learning can produce higher shortterm OKP; slow benchmarking (high knowledge inertia) and moderate mutual learning can achieve higher long-term
OKP [12]. The main outcome indicators are the final course performance and satisfaction with the course [13].

This paper mainly introduces the characteristics of artificial intelligence and the definition of flipped classroom. Based on artificial intelligence and flipped classroom, the hybrid teaching design of mental health education course can be realized through intelligent teaching platform. What advantages does intelligent teaching platform have compared with traditional teaching? Most of the students' interest in learning has improved in the entertainment classroom, which shows that the research method of this article is effective. For the study of other subjects, you can get experience from this article.

\section{Artificial Intelligence and Flipped Classroom}

2.1. Artificial Intelligence. Artificial intelligence is the research and development of the theory, technology, and application system for simulating, expanding, and expanding human intelligence. It is a new technology science with different understanding and definition in different fields. The basic definition of artificial intelligence is to study how to use computer to simulate the human brain's reasoning, identification, understanding, participation, learning, thinking, and problem-solving thinking activities [14]. These unique thinking activities are in the past, only human beings can do it, and its core idea is to make the computer performance more perfect and comprehensive development [15].

Since the introduction of artificial intelligence, people's traditional concepts have been gradually changed, and the level of human knowledge and humanistic education has been improved. In the history of education development, the elimination of the old and the introduction of new technologies often provide a powerful driving force for educational reform, making teaching more convenient and efficient and making education more fair and popular. The teaching software with artificial intelligence can look, listen, speak, and learn like human beings and even understand and feed back the user's emotions or emotions, so that users can communicate with the computer naturally and fluently through language, text, and other ways, so as to realize human-computer interaction [16].

As a computer technology simulating human intelligence, artificial intelligence has the following characteristics:

(1) Artificial intelligence has the ability of learning. It is also an important symbol to judge whether a machine has intelligence. This feature can make intelligence automatically acquire new knowledge, improve practical ability, and adapt to the changing environment. Human beings are some machine learning methods developed according to their own learning ability.

(2) Artificial intelligence needs to have the ability of perception. This kind of intelligent machine perception requires the perception ability similar to human beings [17], that is, to transmit information to the outside world through the senses of vision, hearing, touch, and smell. Its main purpose is to 
improve the perception ability of intelligent machine and realize human-computer interaction.

(3) Artificial intelligence has a certain thinking ability. The artificial intelligence system can record the external information sensed by the sense organs and store the information by itself. In the process of perceiving information, it involves its own basic skills, such as knowledge expression and reasoning. Simulating the human thinking process is the way of intelligent thinking.

(4) Artificial intelligence needs behavioral ability because the perception of the artificial intelligence system is used as the input function module; then the behavior ability of the artificial intelligence system is taken as the output function module. For example, intelligent control is the combination of artificial intelligence technology and traditional automatic control technology, which is unnecessary. In the case of artificial intervention, all have artificial intelligence. The system can be completed independently.

2.2. Flipped Classroom. Flipped classroom originated from Woodland Park High School in the United States. Colorado is located in a remote area. Due to the limitation of living conditions, local students often cannot get to school on time or even miss classes for a long time. In order to help students finish their studies on time, two teachers of the school first thought of uploading teaching videos to the Internet so that students can watch the learning process by themselves and help them master the teaching progress in time [18].

At present, the flipped classroom mode is further defined, which is teachers making video courseware in advance [19], students study at home before class, teachers and students communicate on the problems in the video in class, and complete a variety of effective classroom practice teaching forms. In the flipped classroom teaching mode, teachers are no longer bound by textbooks and courseware and have more energy and time to know the teaching progress, explain, and learn specific problems. The flipped classroom teaching mode does not give the learning task to students but emphasizes the dominant position of teachers. The teaching process of flipped classroom is inseparable from teachers. Teachers are always ready to help students answer questions. Compared with traditional teaching mode, the flipped classroom model has four characteristics:

(1) The change of the roles of teachers and students: under the flipped classroom teaching mode, the teacher transforms from the knowledge transmitter to the student's learning instructor and promoter. Students, as "listeners" and passive receivers of teachers' explanation in class, are transformed into autonomous learners. Flipped classroom mode is a teaching process in which students are the main body of learning.

(2) Teaching process: the flipped classroom teaching process is that students learn content in advance and finish their homework in class. In other words, in the flipped classroom teaching mode, the absorption and understanding of knowledge is completed by students watching the teaching video before class, and the digestion of knowledge is completed through the discussion [12].

(3) Teaching environment: the flipped classroom teaching mode provides a good learning environment for students; they no longer rely on teachers to give lectures in class, but through the teaching video, teaching media and other courseware provided by teachers for autonomous learning before class [15]. For the weak learning ability of students, they can read the content of this class in advance before class, and then the class can follow the teacher's explanation. For students with strong learning ability, when teachers explain what they have understood, they can learn more about what they do not understand. For these two types of learning, you can adjust your learning progress according to your own learning situation.

(4) Teaching resources: the flipped classroom teaching model is that all teachers unite and adopt unified teaching to formulate teaching plans, study, discuss, and record video together and realize the sharing of educational resources for the whole grade. For a specific topic, the teaching video is usually about 10-20 minutes. Through the collective lesson preparation, we can strengthen the communication and communication between teachers and make the recorded course content, difficulty, and class type design more perfect. Teaching resources are open to all teachers and students.

\subsection{Hybrid Teaching of Artificial Intelligence and Flipped} Classroom. Artificial intelligence itself can not have an impact on teaching, but it can be transformed into a medium or tool used by teachers to play a role in education and teaching. The artificial intelligence teaching platform uses big data, cloud computing, and other technologies to realize the comprehensive docking function of teachers, students, and parents [20].

With the advent of Internet plus era and the rapid development of artificial intelligence, many open and intelligent teaching platforms such as Tencent classroom have emerged. Most of the functions of these platforms include video recording, teacher-student interaction, precise teaching, after-school testing, and other functions [21, 22]. In order to promote the progress of teaching mode and teaching means and improve the teaching quality, more and more intelligent teaching platforms are used by teachers, which solves the problems of poor communication and low interaction in the classroom and is recognized by teachers, students, and parents [23]. The intelligent teaching platform has the following characteristics.

2.3.1. Accuracy. With the continuous increase of multimedia demand in schools and the rapid development of learning 
analysis technology, adaptive learning technology has developed into a mature and effective learning technology. It can automatically adapt to the learning situation of different students $[24,25]$. Based on the theory of knowledge space, it decomposes knowledge points and "scores". That is, the simple content of learning, the degree of suffering, and the degree of differentiation predict the learning ability of students, matche learning resources, reduce the repetition rate of students, and accelerate the progress of education [26, 27].

2.3.2. Based on Data. The intelligent education platform uses deep network technology to realize students' efficient learning, continuously collects various data during the students' learning process, and records every progress. In the communication, the intelligent education platform will record one by one and automatically generate a data analysis chart based on the recorded data. Through the intelligent teaching platform, students can browse the records of the interactive process, discover their own shortcomings, and view insufficient knowledge points [28, 29]. Teachers can analyze the habits of users through the data recorded by the intelligent education platform and then help students make learning plans suitable for students, thereby improving students' academic performance [30].

2.3.3. Sharing. Through cloud computing, the intelligent teaching platform can share teachers' lesson preparation resources, recorded teaching videos, and students' learning materials in the cloud. Students can obtain the materials and teaching videos that they do no't know through the intelligent teaching platform and carry out independent learning. The data generated in the learning process of students in the intelligent teaching platform are saved in the cloud, which can be guaranteed to watch at any time. Teachers can view the data of students' learning process and analyze students' learning habits in the intelligent teaching platform [31, 32].

\subsection{University Student Model in Artificial Intelligence Teaching}

2.4.1. Student Learning Interest Model. This article will use the vector space model to represent the learning interest model. In this representation model, students' interest is modeled by recording the learning resources corresponding to student browsing, learning, testing, and other behaviors, and the form of learning resources is defined by feature vectors:

$$
Q=\left\{\left(u_{1}, v_{1}, w_{1}\right),\left(u_{2}, v_{2}, w_{2}\right),\left(u_{n}, v_{n}, w_{n}\right)\right\},
$$

where $u_{i}$ is a feature item that can represent learning resources; $v_{i}$ is the weight of the feature item $u_{i}$ in $Q$; and $w_{i}$ is the category of the feature item. Taking into account the difference in the length of interest, the feature vector is improved, the construction of the learning interest model is defined as

$$
\text { Lif }=\left\{\left(u_{1}, V_{1}^{S}, V_{1}^{L}, t_{1}, t y_{1}, \text { parent }_{1}\right), \ldots,\left(u_{n}, V_{n}^{S}, V_{n}^{L}, t_{n}, t y_{n}, \text { parent }_{n}\right)\right\}
$$

where $V_{1}^{S}$ represents the short-term interest weight of the feature item; $V_{1}^{L}$ represents the long-term interest weight of the feature item; $t_{i}$ is the update time of the long-term interest weight; $t y_{i}$ is the category to which the feature item belongs; and parent ${ }_{1}$ is the parent feature item of the feature item.

Short-term interest represents students' interest in a relatively short period of time, and its calculation formula is shown in the following formula:

$$
V_{1}^{S}=\frac{1}{N} \sum_{j=1}^{N} \frac{1}{S} \sum_{k=1}^{S_{j}} v\left(u_{i}, p_{k}\right)
$$

where $N$ is the statistical time size; $S_{j}$ is the number of students browsing system pages on the $j$ th day; $v\left(u_{i}, p_{k}\right)$ is the weight of the feature item in the current page feature vector $p_{k}$, and the calculation formula is as follows:

$$
v\left(u_{i}, p_{k}\right)=\frac{f\left(u_{i}, p_{k}\right) \times \log \left(\left(m / m u_{i}\right)+0.01\right)}{\sqrt{\sum_{p_{k}}^{u_{i}} u f\left(u_{i}, p_{k}\right) \times \log \left(\left(m / m u_{i}\right)+0.01\right)}} \times \operatorname{const}\left(p_{k}\right) .
$$

where $m u_{i}$ is the number of web pages where the feature item appears, and const $\left(p_{k}\right)$ is an additional parameter of learners' behavior in $p_{k}$. The value formula ofconst $\left(p_{k}\right)$ is obtained from the acquisition of learning interest information as shown in the following formula:

$$
\operatorname{const}\left(p_{k}\right)= \begin{cases}0, & \frac{\operatorname{timep}_{k}}{\operatorname{wnp}_{k}}<\mathrm{TH}, \\ 1, & \frac{\operatorname{timep}_{k}}{\mathrm{wnp}_{k}} \geq \mathrm{TH}, \\ 2, & \text { save, download, print, mark. }\end{cases}
$$

Among them, timep $_{k}$ is the time spent by learners to browse the page; $\mathrm{wnp}_{k}$ is the total number of words on the page or the length of the page content; $\mathrm{TH}$ is the threshold; saving, downloading, printing, and collecting are regarded as one type of behavior; and any one of them is taken only once, without stacking.

Long-term interest is a student's learning interest over a long period of time and generally does not change easily, so it is also the main data source for estimating students' learning interest. However, the interest of students is not permanent. It will change and forget with the passage of time and different levels of students' knowledge. Of course, new 
long-term learning interests will also appear as a short-term interest continues to increase [33, 34]. When assessing longterm interests, time and short-term interests must be integrated, as shown in the following formula:

$$
V_{i}^{l}=V_{i}^{l-\text { pre }} \times e^{-\left(\ln 2 / h \times l^{\text {cur }}\right)\left(d-d_{i}\right)+V_{i}^{S}},
$$

where -pre is the weight of the learner's long-term learning interest before the update and $e^{-\left(\ln 2 / h \times l^{\text {urr }}\right)\left(d-d_{i}\right)}$ is the forgetting factor that indicates that the learning interest gradually weakens with time.

2.4.2. Student Cognitive Ability Model. The input of students' relevant information and their behavior and performance during the test are the key information sources in the CoFSM modeling process of the cognitive ability model $[35,36]$.

(1) Vector Calculation Self-Built Test Results. There are $N$ types of test questions for each knowledge item. When multiple knowledge points are examined, a set of simulated exercises will be formed using the unitized knowledge domain triple random automatic question-building algorithm [37]. After the student has tested a certain type of question multiple times, it will be recorded in the test result table. Suppose that after the student has tested the mental health type question multiple times, the given mental health question cognitive vector is

$$
A B_{i}=\{a b(1), a b(2), a b(3), a b(4), a b(5), a b(6)\} .
$$

Then, the correct usage rate of knowledge point ID $=1$ in mental health questions is $R(\mathrm{a} 1)$ :

$$
R(p 1)=\frac{R 1(1)}{(R 1(1)+R 1(-1))} .
$$

The obtained cognitive ability vector is $\mathrm{QNi}$ :

$$
A N i=R(p 1) * \text { Abi. }
$$

Considering $\mathrm{N}$ types of questions, the student's cognitive ability mastery vector $\mathrm{AN}$ can be obtained when the test knowledge point $\mathrm{ID}=1$ :

$$
A N=\{A N 1, A N 2, \ldots, A N n\} .
$$

Add the weights set by various question types to comprehensively calculate the students' cognitive ability $V$ for this knowledge point:

$$
V=W T * A N
$$

Among them, WT is the weight vector of various question types.

(2) Vector Recording Expert Test Result. Suppose the student tests the multiple choice question type, and calculate the correct rate of the six cognitive abilities of the student in the multiple choice question type according to the recorded vector table and defines it as vector $i$.
It is the correct rate of a certain cognitive ability, calculated as

$$
p_{i}=\frac{R_{i j}(1)}{R_{i j}(1)+R_{i j}(-1)},
$$

where the number of single-choice questions in the $p_{i}$ test and $R_{i j}(1)$ is the total number of correct answers to the $t$-th cognitive ability during this test; on the contrary, $R_{i j}(-1)$ is the total number of incorrect answers.

When testing knowledge points in mental health subjects, the general question types include multiple choice questions, true or false questions, fill-in-the-blank questions, translation questions, and writing questions. Various questions are obtained for each question type combined with the abovementioned computational cognitive ability method $[38,39]$. The matrix $G$ of various cognitive abilities:

$$
G=\left(\begin{array}{ccc}
p_{11} & \cdots & p_{16} \\
\cdots & \cdots & \cdots \\
p_{51} & \cdots & p_{56}
\end{array}\right) .
$$

Add the weight vector B of each question type test and calculate the final cognitive ability evaluation result obtained by the student after the test as $V$ :

$$
V=C * G=\left(V_{1}, V_{2}, V_{3}, V_{4}, V_{5}, V_{6}\right) .
$$

Calculate the comprehensive cognitive ability $M$ obtained by the students during this test:

$$
M=\sum_{i=1}^{6} V_{i} * A_{i}
$$

(3) Comprehensive Calculation of Cognitive Ability. Students choose the form of self-built question bank in unit study to get cognitive ability $V$ and test in expert question bank to get cognitive ability $M$. Finally, the cognitive ability vector $W$ of this knowledge point is

$$
W=\lambda_{1} * V+\lambda_{2} * M
$$

where $\lambda_{1}$ and $\lambda_{2}$ are self-built question bank and expert question bank test to obtain the weight coefficient of cognitive ability in the final cognitive ability.

\section{Experimental Design}

3.1. Experimental Data Collection. This paper selects key 1 class, key 2 class, key 3 class, and key 4 class from the students of our school. The size of these 4 classes is 53-55. The test scores of these classes are similar, which has certain comparative significance. Divide key 1 class, key 2 class, key 3 class, and key 4 into 2 groups randomly, and divide into artificial intelligence and flipped classroom group (key 1 class and key 3 class) and general teaching group (key 2 class and key 4 class)). In order to facilitate identification, the key group 1 and key group 3 are marked as groups A1 and A2. Key 2 class and key 3 class are marked as B1 and B2 groups. 
3.2. Experimental Steps. The steps of the course design are as follows:

(1) First explain the mixed teaching concept of artificial intelligence and flipped classroom psychology with groups A1 and B1, so that students are fully prepared to accept the new hybrid teaching.

(2) The teacher prepares the mental health education textbook, then records the teaching video for 10-20 minutes, uploads it to the intelligent teaching platform, and explains clearly how to log in to the intelligent teaching platform and find the teaching video for learning.

(3) The recorded teaching video will be equipped with a test about the content of teaching video, and the test questions are about 5 . The test can make students understand the content of the teaching video deeply and can also detect whether the students have watched the teaching video carefully.

(4) In order to reflect the students' problems in watching the teaching video, the last question of the test is that is there anything you do not understand? Then, the teacher summarizes the content of the last question and answers the students' questions while giving a lecture on the other day. Increasing the interaction between students and teachers can stimulate students' interest and promote their learning.

(5) According to the students' learning process records and students' performance in the classroom, teachers can analyze students' learning behavior and make better learning plans for students.

(6) In a certain period of time, teachers upload a big test on the intelligent teaching platform to test the students' learning and mastering situation in this period of time, analyze the students' academic achievements, and make the next stage of learning curriculum design for students. For students with poor learning ability, teachers should be more targeted to guide students, to prevent students from falling behind in the learning process. Students can also stage the line of the test, to adjust their learning plan in time, for their own bad knowledge to review and promote students' autonomous learning; general education group: according to the previous teaching method.

\section{Analysis of Experimental Results}

4.1. Comparison of Mental Health Education Learning Attitude. The likes of each group in the study are shown in Figure 1.

It can be seen from the figure that, after this experiment, the acceptance in each group has been improved. The combination has increased the fun of the classroom and further enhancing students' acceptance, which not only improves the quality of education but also enhances the culture. Communication brings positive meaning.

\subsection{Comparison of Mental Health Education Course Scores of} 24 Classes in Midterm Examination. The midterm examination results of groups $\mathrm{A} 1$ and $\mathrm{A} 2, \mathrm{~B} 1$ and $\mathrm{B} 2$ are shown in Table 1.

As shown in Table 1 and Figure 2, the curriculum reform takes school-enterprise cooperation as the motive force and real projects as the link and integrates mental health education course in the integrated curriculum group. The project-related knowledge points and skill points are organized in an orderly manner according to the development process, and we combined teachers' macrothinking advantages, the experience of the company's personnel, the technical advantages, and the support of the company's equipment escort the project, fully linking both inside and outside of class and mobilizing the students' subjective initiative, so that students can gradually understand and adapt to the business operation mode and experience the industry during the project practice. Let students have more professional knowledge, cultivate their professional thinking ability, and lay a solid foundation for their career.

4.3. Comparison of Mental Health Education Course Scores in Final Examination of 4 Classes. The final examination results of groups A1 and A2, B1 and B2 are shown in Table 2.

As shown in Figure 3, the industry applicability of graduates is maximized through the improvement of artificial intelligence talent training programs, the construction of internal and external training bases, and the reformation and deepening of curriculum teaching. Content settings that are out of touch with industry development will only make the training of applicable talents more effective. The best way to obtain local industry development information is for teachers to go deep into the local area.

\subsection{Evaluation of Mental Health Education Course Learning} Effect. Although the final examination scores can show the learning effect of most students at a certain stage, it is only because a single test score is not scientific in determining a person's long-term academic performance. Artificial intelligence and flipped classroom psychology concept is a form of teaching; it does not want to judge a student's cultivation according to the examination results of a student. Instead, it should pay attention to the performance of students in each learning link, rather than in the final examination with partial generality.

In this paper, five people were randomly selected from group A1 and group B1 for evaluation. The evaluation scheme was divided into four stages. While retaining the final part is to cater to the school's unified final assessment system, the students can have a good review and summary of the previous learning content at the end of the semester. Record the students' three learning activities: classroom performance, extracurricular performance, and each integral item of intelligent teaching platform, as shown in Figure 4.

As can be seen from Figure 4, the score of student $J$ 's three learning activities is the highest among 10 students. At the same time, from the beginning of school to the end of the semester, student $J$ made the most progress. $J$ thinks he has made full use of the teacher's resources and will watch the 


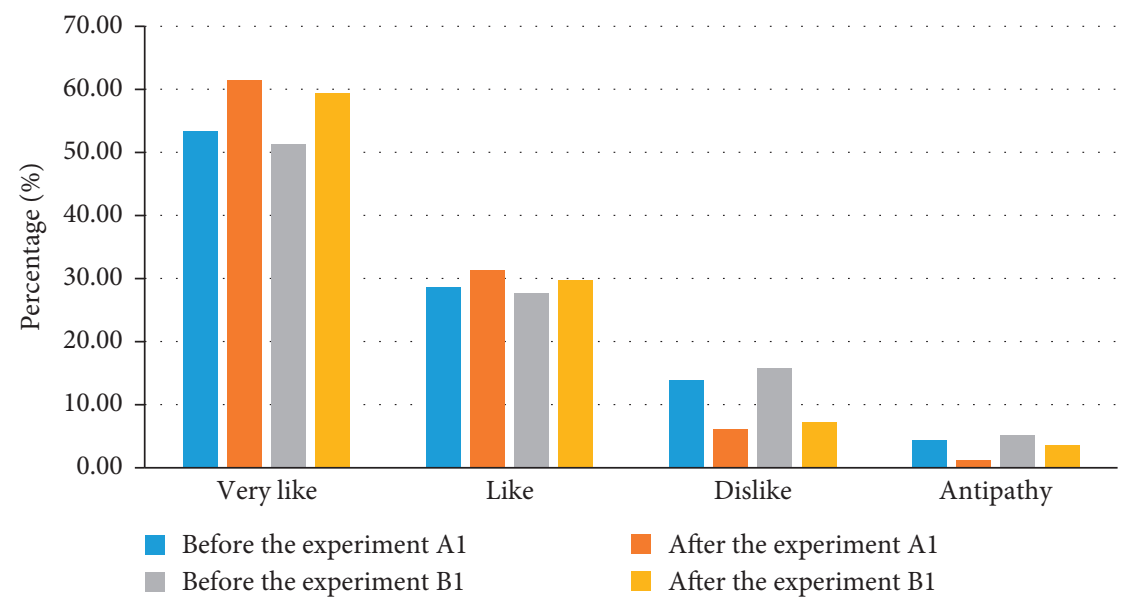

FIgURE 1: Comparison of cultural acceptance of key groups.

TABLE 1: Midterm examination results of 4 classes.

\begin{tabular}{|c|c|c|c|c|c|c|c|}
\hline \multicolumn{8}{|c|}{ Number of people } \\
\hline Group & Class size & Above 130 points & $110-130$ points & $100-110$ points & $90-100$ points & Less than 90 points & Average \\
\hline A1 & 55 & 10 & 20 & 15 & 7 & 3 & 115.65 \\
\hline $\mathrm{A} 2$ & 54 & 6 & 15 & 16 & 11 & 6 & 104.78 \\
\hline B1 & 54 & 9 & 19 & 12 & 10 & 4 & 109.65 \\
\hline B2 & 55 & 5 & 15 & 21 & 10 & 5 & 102.45 \\
\hline
\end{tabular}

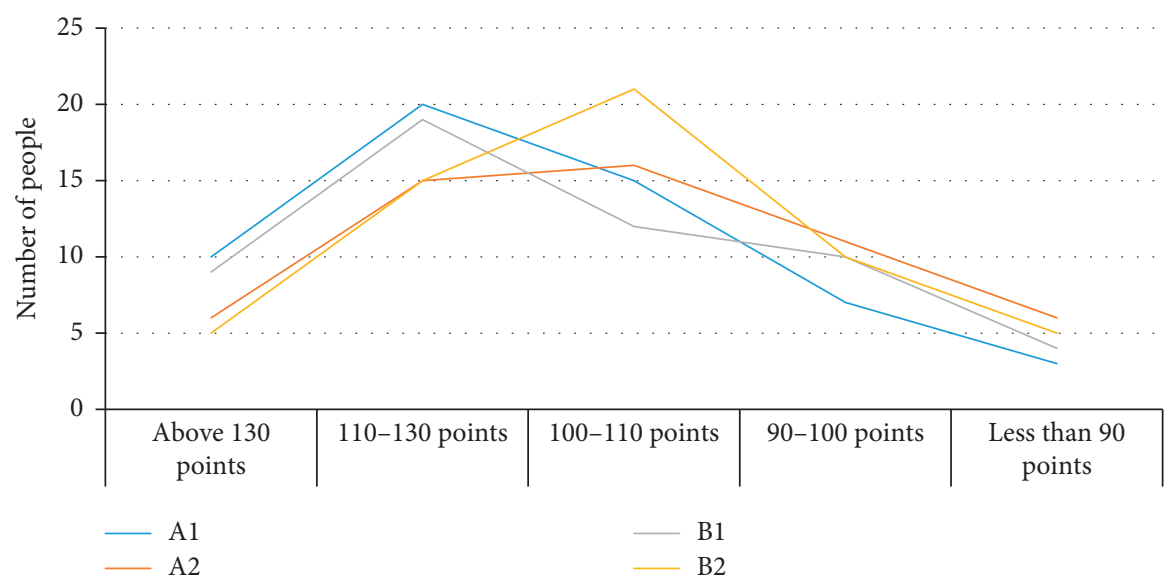

FIgURE 2: The number of students in different classes in different sections.

TABle 2: The final mental health education course scores of 4 classes.

\begin{tabular}{|c|c|c|c|c|c|c|c|}
\hline \multicolumn{8}{|c|}{ Number of people } \\
\hline Group & Class size & Above 130 points & $110-130$ points & $100-110$ points & 90-100 points & Less than 90 points & Average \\
\hline A1 & 55 & 12 & 20 & 17 & 5 & 1 & 118.78 \\
\hline A2 & 54 & 7 & 14 & 18 & 11 & 4 & 104.65 \\
\hline B1 & 54 & 11 & 19 & 15 & 7 & 2 & 116.65 \\
\hline B2 & 55 & 5 & 15 & 20 & 10 & 5 & 102.45 \\
\hline
\end{tabular}

learning videos repeatedly. She also asked that the course resources and videos after the teacher's lecture could also be put on the intelligent teaching platform, so that she could learn the rest of the courses during the holiday. Student $A$ ranked second in the class in all academic achievements. She believes that she has made great progress in mental health 


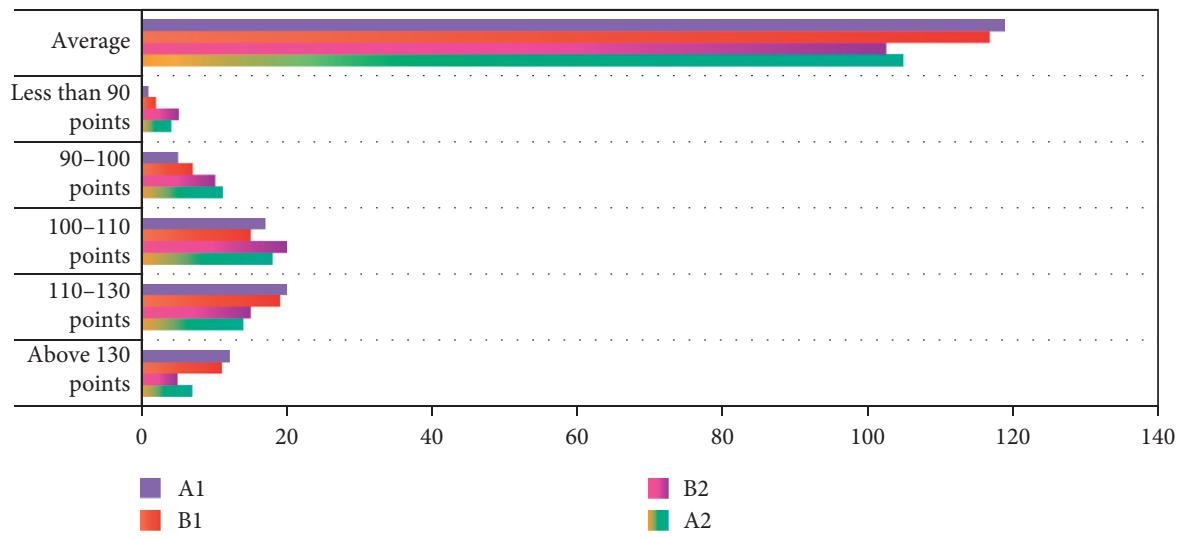

FIgURE 3: The final mental health education course scores of 4 classes.

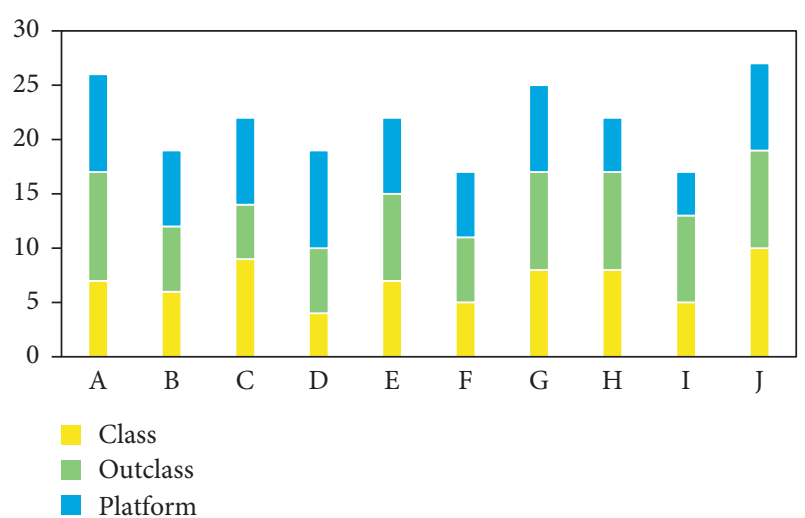

FIGURE 4: Student's points in three learning activities.

education course this semester, and she would like to continue the mixed teaching with the concept of artificial intelligence and flipped classroom psychology in the next semester. It is worth mentioning that, although $J$ and $A$ are the top two students in the class, $J$ did well in the final exam, but $A$ did not. The test results are not the only standard to measure the learning effect. The test results are one-sided and cannot detect all the learning situations. This is especially true for language learning, which requires a comprehensive assessment scheme.

After a semester of artificial intelligence and flipped classroom psychology concept, the artificial intelligence and flipped classroom psychology concept can stimulate students' interest in learning mental health education course more than traditional teaching.

\section{Conclusion}

Artificial intelligence is a sign of the maturity of innovation and entrepreneurship education. In the process of the development of innovation and entrepreneurship practice, each laboratory, instructor team, and student organization have established and formed their own innovation and entrepreneurship practice resources. On this basis, in the college, according to the relevant national policies and regulations, the existing resources are integrated to form an integrated innovation and entrepreneurship practice platform structure system. The key to the implementation of the technological innovation-driven development strategy lies in talents. Innovative development puts forward new and higher requirements for the cultivation of talents in higher education. The Ministry of Education has continuously issued a series of requirements and measures to strengthen the construction of the innovation and entrepreneurship education curriculum system, extensively carry out innovation and entrepreneurship practice activities, improve the quality standards of talent training, cultivate the spirit and ability of innovation and entrepreneurship, and strengthen the practical ability.

This paper mainly introduces the characteristics of artificial intelligence and the definition of flipped classroom. Based on artificial intelligence and flipped classroom, the hybrid teaching design of mental health education course can be realized through intelligent teaching platform. What advantages does intelligent teaching platform have compared with traditional teaching? The fundamental purpose of the innovation and entrepreneurship practice platform is to cultivate and improve students' engineering practice ability, innovative thinking, and entrepreneurial ability. It should be an innovative, open, collaborative and shared innovation and entrepreneurship project incubation platform.

Colleges and universities are the base for constructing innovation and entrepreneurship education for college students, as well as the main place to deepen education reform, innovate curriculum system, and strengthen practical education. The results of the mixed teaching of artificial intelligence and flipped classroom psychology may have some limitations.

\section{Data Availability}

The data that support the findings of this study are available from the corresponding author upon reasonable request.

\section{Conflicts of Interest}

The authors declare that they have no conflicts of interest regarding the publication of the research article. 


\section{Acknowledgments}

This work was supported by the Key Subject of Heilongjiang province's 13th Five-Year Plan for Education Science in 2019: Research on the Connotative Development Path of Application-oriented UniversitiesA Case Study of the Characteristic Application-Oriented Universities in Heilongjiang Province (GJB1320180); the subject of Heilongjiang Province's 13th Five-Year Plan for Education science in 2019: The application of embodied cognition theory in the Cultivation of vocational values of College Students, number: GJC1319021.

\section{References}

[1] H. Lu, Y. Li, M. Chen, H. Kim, and S. Serikawa, "Brain intelligence: go beyond artificial intelligence," Mobile Networks and Applications, vol. 23, no. 2, pp. 368-375, 2017.

[2] S. Wan, Z. Gu, and Q. Ni, "Cognitive computing and wireless communications on the edge for healthcare service robots," Computer Communications, vol. 149, 2020.

[3] M. Q. Raza and A. Khosravi, "A review on artificial intelligence based load demand forecasting techniques for smart grid and buildings," Renewable and Sustainable Energy Reviews, vol. 50, pp. 1352-1372, 2015.

[4] F. Xiao, "Multi-sensor data fusion based on the belief divergence measure of evidences and the belief entropy," Information Fusion, vol. 46, pp. 23-32, 2019.

[5] Y. Chen, W. Zheng, W. Li, and Y. Huang, "Large group Activity security risk assessment and risk early warning based on random forest algorithm," Pattern Recognition Letters, vol. 144, 2021.

[6] Z. Lv, A. Halawani, S. Feng, R. Shafiq Ur, and H. Li, "Touchless interactive augmented reality game on vision-based wearable device," Personal and Ubiquitous Computing, vol. 19, no. 3-4, pp. 551-567, 2015.

[7] Y. Zang, F. Zhang, C. A. Di et al., "Advances of flexible pressure sensors toward artificial intelligence and health care applications," Materials Horizons, vol. 2, no. 2, pp. 25-59, 2015.

[8] M. Elhoseny, G.-B. Bian, S. K. Lakshmanaprabu, K. Shankar, A. K. Singh, and W. Wu, "Effective features to classify ovarian cancer data in internet of medical things," Computer Networks, vol. 159, pp. 147-156, 2019.

[9] H. Morgan, K. Mclean, C. Chapman, J. Fitzgerald, A. Yousuf, and M. Hammoud, "The flipped classroom for medical students," The Clinical Teacher, vol. 12, no. 3, pp. 155-160, 2015.

[10] M. B. Gilboy, S. Heinerichs, and G. Pazzaglia, "Enhancing student engagement using the flipped classroom," Journal of Nutrition Education and Behavior, vol. 47, no. 1, pp. 109-114, 2015.

[11] D. J. Peterson, "The flipped classroom improves student achievement and course satisfaction in a statistics course," Teaching of Psychology, vol. 43, no. 1, pp. 10-15, 2015.

[12] S. B. Tsai, W. Wu, S. Ma, C. H. Wu, and B. Zhou, "Benchmarking, knowledge inertia, and knowledge performance in different network structures," Enterprise Information Systems, vol. 14, 2019.

[13] S. Whillier and R. P. Lystad, "No differences in grades or level of satisfaction in a flipped classroom for neuroanatomy," Journal of Chiropractic Education, vol. 29, no. 2, pp. 127-133, 2015.
[14] Z. Lv, H. A. N. Yang, K. S. Amit, m. Gunasekaran, and 1. haibin, "Trustworthiness in industrial IoT systems based on artificial intelligence," IEEE Transactions on Industrial Informatics, vol. 16, 2020.

[15] N. N. Hurrah, S. A. Parah, N. A. Loan, J. A. Sheikh, M. Elhoseny, and K. Muhammad, "Dual watermarking framework for privacy protection and content authentication of multimedia," Future Generation Computer Systems, vol. 94, pp. 654-673, 2019.

[16] Z. Lv, "Virtual reality in the context of internet of things," Neural Computing and Applications, vol. 32, pp. 1-10, 2019.

[17] J. Yang, C. Wang, B. Jiang, H. Song, and Q. Meng, "Visual perception enabled industry intelligence: state of the art, challenges and prospects," IEEE Transactions on Industrial Informatics, vol. 17, no. 3, p. 2204, 2021.

[18] X. Yuan, D. Li, D. Mohapatra, and M. Elhoseny, "Automatic removal of complex shadows from indoor videos using transfer learning and dynamic thresholding," Computers \& Electrical Engineering, vol. 70, pp. 813-825, 2018.

[19] S. Ding, S. Qu, Y. Xi, and S. Wan, "A long video caption generation algorithm for big video data retrieval," Future Generation Computer Systems, vol. 93, pp. 583-595, 2019.

[20] X. Li, H. Jianmin, B. Hou, and P. Zhang, "Exploring the innovation modes and evolution of the cloud-based service using the activity theory on the basis of big data," Cluster Computing, vol. 21, no. 1, pp. 907-922, 2018.

[21] Q. Wang and P. Lu, "Research on application of artificial intelligence in computer network technology," International Journal of Pattern Recognition and Artificial Intelligence, vol. 33, no. 5, p. 1959015, 2019.

[22] R. Polikar, R. Shinar, L. Udpa et al., "Artificial intelligence methods for selection of an optimized sensor array for identification of volatile organic compounds," Sensors \& Actuators B Chemical, vol. 80, no. 3, pp. 243-254, 2015.

[23] N. Nandhakumar and J. K. Aggarwal, "The artificial intelligence approach to pattern recognition-a perspective and an overview," Pattern Recognition, vol. 18, no. 6, pp. 383-389, 2015.

[24] P. Yeaton, R. J. Sears, T. Ledent et al., "Discrimination between chronic pancreatitis and pancreatic adenocarcinoma using artificial intelligence-related algorithms based on image cytometry-generated variables," Cytometry, vol. 32, no. 4, pp. 309-316, 2015.

[25] S. Makridakis, "The forthcoming Artificial Intelligence (AI) revolution: its impact on society and firms," Futures, vol. 90, pp. 46-60, 2017.

[26] F. Goyache, J. J. Del Coz, J. R. Quevedo et al., "Using artificial intelligence to design and implement a morphological assessment system in beef cattle," Animal Science, vol. 73, no. 1, pp. 49-60, 2016.

[27] J. Hill, W. Randolph Ford, and I. G. Farreras, "Real conversations with artificial intelligence: a comparison between human-human online conversations and human-chatbot conversations," Computers in Human Behavior, vol. 49, pp. 245-250, 2015.

[28] J. J. Ye, "Artificial intelligence for pathologists is not near- it is here: description of a prototype that can transform how we practice pathology tomorrow," Archives of Pathology \& Laboratory Medicine, vol. 139, no. 7, pp. 929-935, 2015.

[29] S. Khokhar, A. A. B. Mohd Zin, A. S. B. Mokhtar, and M. Pesaran, "A comprehensive overview on signal processing and artificial intelligence techniques applications in classification of power quality disturbances," Renewable and Sustainable Energy Reviews, vol. 51, pp. 1650-1663, 2015. 
[30] R. Liu, B. Yang, E. Zio, and X. Chen, "Artificial intelligence for fault diagnosis of rotating machinery: a review," Mechanical Systems and Signal Processing, vol. 108, pp. 33-47, 2018.

[31] A. F. Chen, A. C. Zoga, and A. R. Vaccaro, "Point/counterpoint: artificial intelligence in healthcare," Healthcare Transformation, vol. 2, no. 2, pp. 84-92, 2017.

[32] S. A. Harrington, M. V. Bosch, N. Schoofs, C. Beel-Bates, and K. Anderson, "Quantitative outcomes for nursing students in a flipped classroom," Nursing Education Perspectives, vol. 36, no. 3, pp. 179-181, 2015.

[33] N. T. T. Thai, B. De Wever, and M. Valcke, "The impact of a flipped classroom design on learning performance in higher education: looking for the best "blend" of lectures and guiding questions with feedback," Computers \& Education, vol. 107, pp. 113-126, 2017.

[34] M. Eaton, "The flipped classroom," The Clinical Teacher, vol. 14, no. 4, pp. 301-302, 2017.

[35] E. Blair, C. Maharaj, and S. Primus, "Performance and perception in the flipped classroom," Education and Information Technologies, vol. 21, no. 6, pp. 1465-1482, 2016.

[36] S. E. Park and T. H. Howell, "Implementation of a flipped classroom educational model in a predoctoral dental course," Journal of Dental Education, vol. 79, no. 5, pp. 563-570, 2015.

[37] X. Li, "The construction of intelligent English teaching model based on artificial intelligence," International Journal of Emerging Technologies in Learning (iJET), vol. 12, no. 12, p. 35, 2017.

[38] X. Research, "On the intelligent English multimedia teaching resources based on the data mining," International English Education Research: English Version, vol. 2019, no. 2, pp. 50-52, 2019.

[39] Y. Yu, F. Li, S. Zhao et al., "Virtual experiment method for MOOC to solve teaching practice skills and difficult points," Control \& Intelligent Systems, vol. 47, no. 2, pp. 77-82, 2019. 